\title{
Serum and Urinary Biomarkers of Acute Kidney Injury
}

\author{
Barbara Lisowska-Myjak \\ Department of Biochemistry and Clinical Chemistry, Medical University of Warsaw, Warsaw, Poland
}

\section{Key Words}

Acute kidney disease $\cdot$ Urinary proteins $\cdot$ Cystatin $C$.

$\mathrm{N}$-acetyl- $\beta$-D-glucosaminidase $\cdot$ Neutrophil

gelatinase-associated lipocalin • Interleukin $18 \cdot$

Kidney injury molecule 1

\begin{abstract}
Acute kidney injury (AKI) is a frequent clinical problem in critically ill patients and the associated mortality is high. Standard serum and urine biomarkers are insensitive and nonspecific for the detection of kidney injury in its early stages which limits the therapeutic options and may compromise the outcome. The study presents new candidates for biochemical markers of AKI, with potentially high sensitivity and specificity, causally related to its pathogenesis and development. Some of these biomarkers measured in serum or urine are well known in laboratory practice but have been used in other tests, while some novel biomarkers have been proposed as a result of experimental and clinical studies. In current clinical practice, identification and classification of AKI is based on elevations in serial serum creatinine concentrations, which are delayed and therefore unreliable in the acute setting. The most promising of the new serum AKI markers are cystatin $C$, neutrophil gelatinase-associated lipocalin and uric acid. Urinary AKI markers may be classified as enzymes released from damaged tubular cells (alkaline
\end{abstract}

phosphatase, $\gamma$-glutamyl transpeptidase, alanine aminopeptidase, isoenzymes of glutathione transferase, $\mathrm{N}$-acetyl$\beta$-D-glucosaminidase), low-molecular-weight proteins $\left(\alpha_{1^{-}}\right.$ microglobulin, $\beta_{2}$-microglobulin, retinol-binding protein, cystatin C) and proteins specifically produced in the kidney and associated with the development of AKI [cysteine-rich protein 61, neutrophil gelatinase-associated lipocalin, kidney injury molecule 1, cytokines and chemokines (Gro- $\alpha$, IL-18), and structural and functional proteins of renal tubules (F-actin, $\mathrm{Na}^{+} / \mathrm{H}^{+}$exchange isoform 3)]. Based on the different expression of these markers, using a panel of serum and urine markers may potentially help to distinguish between various types of insults, establish the duration and severity of injury, predict the clinical outcome and help to monitor response to treatment in AKI.

Copyright $\odot 2010$ S. Karger AG, Basel

Acute kidney injury (AKI) is generally defined as an abrupt and sustained decline in renal function, causing a steady accumulation of nitrogenous and nonnitrogenous products and toxins, with rapid development of fluid, electrolyte and acid-base disorders. The incidence and mortality rates are high and the search for effective treatment continues. The frequency of AKI occurrence varies from $5 \%$ on the inpatient wards to $30-50 \%$ in patients from intensive care units. The hospital mortality rate among in-

\section{KARGER}

Fax +4161306 1234 E-Mail karger@karger.ch www.karger.com
(C) 2010 S. Karger AG, Basel

0253-5068/10/0294-0357\$26.00/0

Accessible online at:

www.karger.com/bpu
Dr. Barbara Lisowska-Myjak, $\mathrm{PhD}$

Department of Biochemistry and Clinical Chemistry

Medical University of Warsaw, ul. Banacha 1

PL-02-097 Warsaw (Poland)

Tel./Fax +48 225720 735, E-Mail basia.myjak@interia.pl 
tensive care unit patients who develop AKI is 5-fold higher than in patients without such a complication [1-7].

The large variations in the reported incidence and mortality rates probably reflect the lack of a uniform definition for AKI. The Acute Dialysis Quality Initiative Working Group suggested standardizing the definition of AKI in adults, using a new system to classify the clinical symptoms of the condition and laboratory markers of kidney function $[2,8,9]$. The consensus classification RIFLE (risk, injury, failure, loss, and end-stage renal disease) defines three grades of severity [risk (class R), injury (class I) and failure (class F)], and two classes of clinical outcome (loss and end-stage kidney disease). The RIFLE criteria, based upon determinations of serum creatinine, are a useful way of assessing successive stages of insufficiency development, but creatinine measurements have a too low sensitivity for detecting early intrarenal lesions $[1,9,10]$.

The devastating course of AKI explains the growing interest of clinicians in effective protection against the consequences of the disease, based upon its early detection and assessment of the clinical course and prognosis, allowing institution of effective treatment $[11,12]$. A particularly acute diagnostic problem is the lack of biochemical markers for early kidney injury that are sensitive and easily applicable in clinical practice and may help to predict the development of AKI.

\section{Pathogenesis and Development of AKI}

AKI is characterized by a sudden reduction in the glomerular filtration rate (GFR) as well as slow and permanent loss of the most affected nephrons. The main cause is the acute apoptosis of renal tubular cells. In some $80 \%$ of AKI patients, necrosis of tubular cells is found, but not acute disease of glomeruli or parenchyma. In clinical practice, the terms AKI and acute tubular necrosis (ATN) are often mistakenly used as synonyms. The term ATN must be limited to the condition which is confirmed by renal biopsy and that is often impossible in critically ill patients $[4,5,9,12,13]$.

Epidemiologic studies have revealed a wide variety of etiologic and risk factors for AKI and their association with chronic kidney disease. ATN may result from oxygen deficiency (e.g. shock, extensive surgical procedures on the major blood vessels and heart, kidney transplantation), septic or toxic kidney injury (e.g. by radiocontrast agents or antibacterial, antimycotic or cytotoxic drugs) $[1,4,13-15]$.

\section{Ideal Biomarker for Diagnosing AKI}

Over the last decade, numerous new markers, measured in blood and urine, satisfying specific requirements for diagnosing AKI have been presented $[2,4,11$, $13,15,16]$.

An ideal biomarker for AKI should:

(1) be highly organ-specific and allow differentiation between intrarenal, prerenal and postrenal causes of AKI and acute renal glomerular injury. In clinical practice, the best available test as yet for the differentiation of intrarenal AKI from prerenal lesion has been the fractional excretion of filtered sodium and urinary sediment assessment. In prerenal lesion, the sediment is normal while in intrarenal injury, it contains epithelial cells from tubules, and granular, leukocyte and waxy casts;

(2) allow recognition of the etiology of AKI (hypoxia, toxins, sepsis, or a combination of these factors);

(3) correlate with the histological findings in kidney biopsy specimens;

(4) be site-specific to detect early injury and identify pathological changes in various segments of renal tubules (the pathogenesis of AKI involves injuries affecting different sites within renal tubules);

(5) correlate with the degree of tubular injury and have high sensitivity for early detection of minor changes and the onset of more severe damage. Such a marker should be detectable throughout the entire course of AKI with defined threshold values to assess progression and regression of renal injury. So far, there has been no good method for differentiating benign, mild, moderate, or severe renal dysfunction;

(6) the investigation should be noninvasive, and

(7) the relevant laboratory tests should be simple and quick to perform, accurate, reliable, inexpensive and commonly available allowing serial assessment of a large number of samples.

\section{Biomarkers of AKI Measured in Serum}

Nitrogenous compounds accumulated in blood, blood urea nitrogen (BUN) and serum creatinine are routinely used standard markers for early stages of AKI. In clinical practice, AKI is detected when serum creatinine concentrations increase over a short period of time, with or without oliguria. Measurements of markers for AKI in serum may be especially useful in patients with severe oliguria and potential changes in urinary biomarker concentra- 
tions induced by hydration status and diuretic therapy $[1$, $2,17]$.

However, increasing evidence from published studies indicates that the creatinine concentration is not a decisive marker in diagnosing AKI $[1,7,10,18,19]$ :

(1) elevated serum creatinine concentrations are not specific for AKI and require differentiation from other prerenal or extrarenal causes of azotemia;

(2) serum creatinine concentrations are not specific for renal tubular lesions, pathogenetically related to AKI development, but seem to reflect the loss of glomerular filtration function, accompanying the development of AKI;

(3) increases in serum creatinine are detected later than the actual GFR changes as creatinine accumulates over time;

(4) serum creatinine is a poor marker of kidney dysfunction as changes in its concentrations are neither sensitive nor specific in response to slight GFR alterations and become apparent only when the kidneys have lost $50 \%$ of their functional capacity, and

(5) changes in serum creatinine may be influenced by other factors, which are not directly related to kidney damage, such as age, sex, body mass, and hydration and nutritional status.

Neutrophil gelatinase-associated lipocalin (NGAL), a $25-\mathrm{kDa}$ protein covalently bound to gelatinase from human neutrophils and determined in serum, has emerged as a sensitive, specific and highly predictive early biomarker for AKI. Serum NGAL measurements predict AKI following cardiopulmonary bypass and radiocontrast agent administration and are a highly sensitive but nonspecific predictor of AKI in critically ill children with septic shock. In the early phases of AKI from diverse etiologies, NGAL accumulates within 2 distinct pools, namely a systemic and a renal pool. Additional contributions of this parameter to the systemic pool in AKI may derive from neutrophils, macrophages and other immune cells. Besides, a decrease in the GFR resulting from AKI would be expected to decrease the clearance of NGAL with further accumulation in the systemic pool. Serum NGAL concentrations greater than $25 \mu \mathrm{g} / \mathrm{l}$ reliably predicted AKI in children [17, 20, 21].

Cystatin C, determined in serum, is an endogenous marker of kidney function, detected earlier than creatinine. It is both to help diagnose renal dysfunction and to identify progress of AKI. Cystatin C is a nonglycosylated protein, an endogenous inhibitor of cysteine proteinases, produced by all nucleated cells of the body and released into the bloodstream at a constant rate. Serum cystatin C concentrations are independent of age, sex, race, body mass and hydration level, and may be measured by a simple nephelometric method. A relatively high concentration in body fluids, low molecular weight $(13.3 \mathrm{kDa})$, and positive charge of the protein molecule facilitate its free glomerular filtration into primary urine. It is completely reabsorbed and catabolized in proximal tubular cells. Due to the constant rate of its production, the assessment of serum cystatin $\mathrm{C}$ concentrations may be a marker of glomerular filtration, which is not affected by infection, liver disease or inflammation $[2,4,22]$.

Serum concentrations of cystatin $\mathrm{C}$ may be used to detect renal dysfunction in critically ill patients with AKI 24-48 h earlier than creatinine measurements. However, cystatin $\mathrm{C}$ is not diagnostically specific for AKI, because it is an early marker of impaired glomerular filtration rather than of tubular lesion $[4,18]$.

Recently, many authors have proposed serum uric acid measurements for early detection and assessment of AKI development. Much is known about the association between hyperuricemia and acute urate nephropathy, but increased serum concentrations of uric acid have also been demonstrated in many other types of AKI. Since elevated serum uric acid concentrations result from its increased production (the effect caused by ischemia, for example) as well as decreased glomerular filtration which reduces its excretion with urine, it is believed that uric acid detected in serum may be a simple marker of imminent onset of AKI.

The increased glomerular filtration of uric acid into primary urine results in supersaturation of intratubular fluid with uric acid, its crystallization with subsequent occlusion of the tubular lumen, and development of local kidney inflammatory response, with infiltration by inflammatory cells. Uric acid is not only a diagnostic marker, but also a biologically active indicator of intrarenal injury to the microvasculature, a potent regulator of endothelial NO levels, and inhibitor of proliferation and migration of epithelial cells, causing endothelial cell apoptosis and stimulation of the proinflammatory agents: monocyte chemoattractant protein 1 and C-reactive protein $[23,24]$.

\section{Urine as Clinical Material for the Detection of Biomarkers for AKI}

Urinanalysis is a traditional noninvasive method used to diagnose, characterize the course of, and predict the clinical outcome of numerous renal diseases. Recently, 
the usefulness of new laboratory markers determined in urine for diagnosing AKI has been assessed. Some of these enzymes and proteins are well known in the medical laboratory as they have been routinely used in other diagnostic tests while some were investigated in recently published studies, aiming at finding markers specifically related to AKI. The latest markers are genes, which are induced early after ischemia, obtained under experimental conditions in cell cultures or tests on animals. The progress of molecular biology techniques, such as urine proteome analysis, offers a reliable tool for the investigation of protein spots, which are directly related to the pathogenesis and development of AKI $[7,11,19]$.

The biomarkers of AKI measured in urine should have the following characteristics:

(1) diagnostic specificity for detecting lesions of renal tubules;

(2) allow early detection of kidney lesions (before increases in serum creatinine and BUN are observed);

(3) their urine concentrations must correlate with acuteness of renal disease;

(4) allow prediction of disease development and unfavorable clinical outcome, and

(5) facilitate prompt decisions to select the best treatment option(s).

AKI markers proposed in the scientific literature may be classified into 3 groups:

(1) enzymes released from necrotic/apoptotic, damaged or dysfunctional renal tubule cells and excreted into urine;

(2) urinary low-molecular-weight proteins $(<40 \mathrm{kDa})$, whose presence in urine reflects their impaired reabsorption from primary urine by proximal tubular cells, and

(3) proteins specifically produced in the kidney in the course of AKI, shown in experimental studies on animal models and in humans, using advanced technologies (genomics, proteomics) to search for genes and their products as AKI markers.

\section{Urinary Enzymes of Renal Origin}

So far, there have been many attempts to use enzymes released from damaged tubular cells and excreted into urine as markers of kidney damage. An obvious diagnostic benefit of determining tubular enzymes in urine results from the fact that they are produced in distinct locations in the cell internal structure, such as the cytoplasm, lysosomes or cell membrane. Accordingly, their measure- ments may provide detailed information about the nature, size and site of the damage to tubular cells and their possible necrosis or dysfunction $[4,5]$.

Alkaline phosphatase, $\gamma$-glutamyl transpeptidase, and alanine aminopeptidase are enzymes of the brush border. Their increased excretion into urine reflects damage of the brush border membrane, with loss of the microvilli. A technical difficulty in the determination of the enzymes is related to their relatively low stability (the measurement must be performed within $4 \mathrm{~h}$ after urine collection), and the need to remove interfering substances from the urine sample by filtration through a chromatographic column before the actual analysis is performed [5].

Isoenzymes of glutathione transferase (GST) are cytoplasmic enzymes. GST- $\alpha$ is formed in epithelial cells of the proximal tubule and GST- $\pi$ in the distal tubule. Increases in urinary excretion of GST- $\alpha$ and GST- $\pi$, which may be different for each, may indicate the location of the lesion. In critically ill patients with AKI, high sensitivity and specificity of the enzymes have been demonstrated. They are predictors of unfavorable AKI development requiring kidney replacement therapy. Correct storage of urine samples for GST measurements requires addition of agents stabilizing the enzyme activity $[4,5,13,25]$.

$\mathrm{N}$-acetyl- $\beta$-D-glucosaminidase (NAG), a lysosomal enzyme, the most active glucosidase in lysosomes of proximal tubular epithelial cells, is a specific urinary marker for the tubular cells because of its relatively high molecular weight $(>130 \mathrm{kDa})$ which precludes filtration of the enzyme by glomeruli. In the course of active kidney disease, urinary NAG levels remain persistently elevated. The increase in urinary NAG activity indicates damage to tubular cells, although it can also reflect increased lysosomal activity without cellular damage $[4,6]$.

Excretion of the enzymes with urine is a very sensitive marker of damage to renal tubules, and appears to be directly correlated with increased serum creatinine concentrations and reduced GFR. Enzymuria occurs sooner and is a more sensitive diagnostic marker than tubular proteinuria. It may also be useful for determining the time that elapsed from the moment the damage occurred as significant increases in alanine aminopeptidase and cysteine-rich protein 61 (CYR61) are observed as early as the first day of kidney injury, decreasing in the later phase of the disease, despite continued injury. In spite of a clear association between enzymes excreted into urine and site-specific lesions to nephron cells, the predictive value of enzyme concentrations for AKI development is relatively low. The usefulness of enzymuria as a marker is 
limited by very low sensitivity thresholds for release of tubular enzymes, which admittedly indicate the injury to tubular cells, but do not identify the cause or reversibility of that process. It seems that using the highly sensitive enzymes of renal tubules for the detection and monitoring of kidney lesions in patients with AKI is justified in the earliest phase of the disease, when the patient is admitted to hospital or up to 4 days before standard blood markers of kidney function increase. Such investigations may identify patients at high risk of developing AKI, allowing earlier introduction of therapy.

The use of NAG determined in urine as a marker of kidney lesion in the course of AKI deserves particular attention. Similarly to other enzymes of tubular origin, it is too sensitive for diagnosing AKI, although a high NAG activity in urine, persisting over a longer period, has been correlated with worse prognosis of disease development and need for kidney replacement therapy. The example of this enzyme raises the question of whether a change in establishing diagnostic sensitivity thresholds for other enzymes may also effect a change in the interpretation of their presence in urine in the course of AKI.

Enzymatic activity in urine is determined by routine, cheap and widely available laboratory methods with the use of specific substrates for each enzyme, while the variations in absorbance of the hydrolysis products are measured spectrophotometrically. However, separate measurement of the $\alpha$ and $\pi$ isoforms of GST in urine requires the use of ELISA. Rapid inactivation of the enzymes in urine samples requires special conditions for the collection and storage of material before the measurements are performed $[4,5,13,25]$.

\section{Urinary Low-Molecular-Weight Proteins}

Low-molecular-weight proteins $(<40 \mathrm{kDa})$, produced by most cells of the body and excreted into the bloodstream, undergo free filtration into primary urine, and complete reabsorption in proximal tubular cells. Increased urinary concentrations of these proteins (tubular proteinuria) may be a practical indicator of overloading the tubular cells with proteins or of their lesion and dysfunction. The low-molecular-weight proteins which have been best characterized for detecting lesions of proximal tubules are $\alpha_{1^{-}}$and $\beta_{2}$-microglobulin, retinol-binding protein (RBP) and cystatin C $[4,13,19,26]$.

$\alpha_{1}$-Microglobulin (molecular weight $31 \mathrm{kDa}$ ) is a protein synthesized by the liver and readily bound to serum immunoglobulin A. Only its free unbound forms are fil- tered by the glomerulus and reabsorbed in proximal tubular cells.

$\beta_{2}$-Microglobulin (molecular weight $12 \mathrm{kDa}$ ) is a protein homologous to histocompatibility antigens, filtered freely by the glomerulus into primary urine. Increased urinary concentrations of $\beta_{2}$-microglobulin have been demonstrated with nephrotoxic agents (radiocontrast agents) or hypoxia caused by extensive cardiosurgical procedures or kidney transplantation, but it is a poor predictor of need for kidney replacement therapy. A technical difficulty involved in the determination of $\beta_{2}$-microglobulin in urine is instability of the protein at $\mathrm{pH}<6$ and alkalization of collected urine samples is required.

RBP (molecular weight $21 \mathrm{kDa}$ ) is a protein bound to some degree to plasma prealbumins, transporting vitamin A. It is easily filtered by the glomerulus, and almost completely reabsorbed in proximal tubules. Even a minor reduction in the renal tubule function may lead to increased excretion of the protein with urine. An advantage of RBP over $\beta_{2}$-microglobulin as a biomarker is RBP stability at low $\mathrm{pH}$ values.

Cystatin C (molecular weight $13 \mathrm{kDa}$ ) is easily filtered by the glomerulus, and reabsorbed and catabolized, but not secreted by renal tubules. Cystatin $\mathrm{C}$ is measured in urine in trace amounts and is not affected by nonrenal factors, such as age or body mass. As it is not subject to the circadian variations, cystatin $\mathrm{C}$ may be determined in single urine samples. The urinary cystatin C:creatinine ratio is a good indicator of renal tubular dysfunction. With impaired renal tubular function, urine cystatin C concentrations may increase up to 200 -fold. Increased excretion of cystatin $\mathrm{C}$ in the urine of patients with AKI may predict unfavorable AKI development and need for kidney replacement therapy as soon as the initial phase of the disease, without oliguria, providing a chance of preventing progression of the disease. High stability of cystatin $\mathrm{C}$ has been demonstrated under routine storage conditions.

It is presumed that tubular proteinuria is a better predictor than enzymuria of need for kidney replacement therapy in the course of AKI [13]. Measurements of urinary concentrations of low-molecular-weight proteins are performed by ELISA.

\section{AKI Markers Specifically Produced in the Kidney}

Specific biomarkers for AKI determined in urine can be classified into three categories. 


\section{(1) Protein Products of Genes Specifically}

\section{Related to AKI}

Experimental research carried out in cultures of human proximal tubular cells, as well as in animals, revealed genes, which undergo early induction and manifold increase after ischemia. Protein products of these genes [CYR61, NGAL, kidney injury molecule 1 (KIM-1)] may serve as new markers for the assessment of AKI [2, $12,27-29]$.

CYR61 is a cysteine-abundant heparin-binding protein, a member of the family of extracellular growth factors. It displays local action, is closely attached to the cell and extracellular matrix. As a signaling molecule it is capable of performing many functions and plays a protective role in the processes of repair and neovascularization.

As a consequence of kidney ischemia CYR61 mRNA is induced in proximal tubular cells, while CYR61 is excreted with urine. In experimental studies, the increases in urinary CYR61 concentration occurred approximately 3-6 h after a 30-min kidney ischemia, with a peak after 6-9 h. Elevated levels were maintained for $24 \mathrm{~h}$ and decreased on follow-up, despite the persistence of lesion. Due to a fast induction, urinary CYR61 concentration may be an early marker of renal lesion, helpful for establishing effective protective therapy $[4,28,30]$.

NGAL is expressed in very low concentrations in numerous human tissues, including the kidney. In the kidney, the NGAL gene is strongly induced after its injury by ischemia, sepsis or nephrotoxins. In the postischemic kidney, NGAL is upregulated in many segments of the nephron, with accumulation mainly in the proliferating cells of the proximal tubule. The biological role of NGAL remains unclear. NGAL might be expressed by the damaged tubule to induce re-epithelization and to reduce apoptosis. A protective effect of NGAL may probably result from the participation of the protein in binding, transport or storage of ferric complexes [4, 11, 27].

Experimental studies demonstrated the effect of the severity and duration of kidney ischemia on increases in urinary concentration of NGAL. In humans, increased NGAL expression has been demonstrated as early as $2 \mathrm{~h}$ after a cardiosurgical procedure, while increased NGAL concentrations in urine preceded increases in serum creatinine. In adults with AKI, a 10-fold increase in NGAL serum concentrations has been demonstrated as well as more than a 100 -fold increase in its urinary levels. NGAL concentrations in both serum and urine correlated with serum creatinine concentrations. Such observations allow the hypothesis that the concentration of NGAL in urine is a sensitive, highly predictive, early marker, differentiating acute prerenal insufficiency from AKI or chronic renal disease $[2,7,12,17,27,32]$.

KIM-1 is a recently detected protein of tubular origin. In a healthy kidney, KIM-1 is not detectable, whereas under experimental conditions, employing molecular biology techniques, KIM-1 has been recognized, both in animals and in humans, as having the features of a marker of ischemic and toxic acute injury of proximal tubular cells. KIM-1 is a type 1 transmembrane protein with extracellular immunoglobulin and highly O-glycosylated mucin subdomains. The extracellular ectodomain of KIM-1, detached by metalloproteinases and excreted into urine, is a quantitative marker of AKI. The increased expression and enhanced synthesis of KIM-1 occur mainly in the areas of tubulointerstitial lesions, with inflammation and fibrosis. In acute proteinuria, the induction of KIM-1 in tubules increases. On the other hand, due to the ability to interact with other proteins, it may actively modulate the processes related to damage or repair.

The ectodomain of KIM-1 in urine is a promising, sensitive, and specific marker of AKI in humans, virtually unaffected by the physical and chemical properties of urine and urine components. At least a 5-fold increase in KIM-1 levels in urine was demonstrated, as early as the first day after toxic lesion of renal tubules, whereas BUN and serum creatinine levels increased as late as the third day. A substantial increase in KIM-1 excretion with urine occurs a few hours after cardiosurgical procedures. Increased excretion of KIM-1 with urine is more specific for ischemic kidney injury and is practically independent of the type of chronic kidney disease or urinary tract infection. A high concentration of KIM-1 in urine predicts compromised outcome in patients with AKI $[2,4,11,15$, $29,33,34]$.

\section{(2) Urinary Cytokines and Chemokines}

The immune response plays a key role in the pathogenesis of ischemic damage to the kidney in AKI. It involves inherent demand for increased renal production of mRNA as well as related proinflammatory chemokines and cy tokines. In most studies, cytokines are determined in serum or plasma, although their measurement in urine may be a simpler and easier alternative. Cytokines and chemokines are nonspecific parameters as they also increase in sepsis and diseases of the liver and lungs, without accompanying kidney injury. The prognostic role of urinary cytokine measurements is unclear in various stages of the disease, as is their role as predictors of fatal outcome in critically ill patients. Gro- $\alpha$ and IL-6, IL-8 
and IL-18 are these urinary cytokines which are thought to be especially suitable for the diagnosis of AKI $[11,19]$.

Gro- $\alpha$ is a human analogue of mouse keratinocytederived chemokine. In kidney injury, experimentally induced in mice, increased concentrations of keratinocytederived chemokine in serum and urine occurred as the first, and were maintained the longest among the 18 selected cytokines and chemokines. The concentrations of keratinocyte-derived chemokine in serum and urine reached their peak levels $3 \mathrm{~h}$ after ischemia, whereas histological changes were evident after $1 \mathrm{~h}$ and serum creatinine concentrations increased as late as $24 \mathrm{~h}$ after the initial ischemic renal insult.

Determination of Gro- $\alpha$ in urine is believed to be a marker for early diagnosis and prediction of development of ischemia-induced AKI. The urinary Gro- $\alpha$ concentrations increased significantly in kidney transplant patients who required dialysis but not in subjects with good graft function [16].

IL-18 is a proinflammatory cytokine, a mediator of inflammation and ischemic tissue damage in many organs. It may act as a neutrophilic attractant and plays an important role in the pathophysiology of sepsis. Experimental studies in animals with induced acute ischemic tubular necrosis revealed that caspase-1-mediated activation of intracellular IL-18 is responsible for kidney injury in the course of AKI, regardless of the role of neutrophils. The source of caspase- 1 and IL-18 in AKI are ischemic cells of the proximal tubule $[2,4,35,36]$.

IL-18 determined in urine is a simple, reliable, accurate, and inexpensive test for the early detection of kidney injury caused by ischemia or nephrotoxins, which allows exclusion of prerenal azotemia, chronic kidney disease and urinary tract diseases. It is a valuable tool to diagnose the severity of AKI and the probability of fatal outcome in critically ill patients without sepsis. IL-18 determination in urine has a sensitivity and specificity of $>90 \%$ for diagnosing AKI in humans. Increased urine IL-18 concentrations in a heterogeneous population of critically ill adults, and in children after cardiosurgical procedures occurred 24-48 h before diagnosing AKI and were related to aggravation of the condition $[2,17,37,38]$.

\section{(3) Structural and Functional Proteins of the}

Renal Tubule

An important cause of structural, biochemical, and functional lesion of proximal tubular cells in AKI is the depolymerization of actin. The lesion of tubules in the course of AKI is also manifested by increased excretion with urine of sodium transporters, placed along the nephron, mainly $\mathrm{Na}^{+} / \mathrm{H}^{+}$exchanger isoform 3 (NHE3) $[4,19]$.

F-actin. The apical membrane of proximal tubular cells is extremely sensitive to ischemia, reacting by rapid (within $5 \mathrm{~min}$ ), duration-dependent structural alterations, resulting from depolymerization of actin contained in the microvilli. Actin-depolymerizing factor (ADF), a $19-k D a$ phosphorylated protein-binding actin, is responsible for the control of actin rupture dynamics. Ischemia causes $\mathrm{pH}$ drop with generalized protein dephosphorylation. The $\mathrm{pH}$-dependent process of ADF dephosphorylation activates that protein, which is subsequently responsible for attachment, depolymerization and detachment of F-actin in the apical part of the cell, being the cause of microvillous destruction. Under physiological conditions, neither ADF nor actin is detected in urine, while after $30 \mathrm{~min}$ of hypoxia the urine samples were found to contain both [39].

NHE3 is the most abundant sodium transporter in renal tubules, located in the apical membrane and subapical endosomes of renal proximal tubular cells, responsible for $60-70 \%$ of reabsorption of the filtered sodium and bicarbonate.

The observed drop in tubular sodium reabsorption in the course of AKI suggested that the profile of sodium transporters placed along the nephron may be a useful urinary marker used for the detection and classification of AKI. Reduced expression of NHE3 in the kidney and a significant correlation between urinary excretion of NHE3 and clinical features of AKI in experimental ATN suggest the loss of that sodium transporter with urine. Increased urinary NHE3 protein excretion may be regarded as a specific marker of acute tubular lesion, used to differentiate ischemic or toxic AKI from other kidney diseases and prerenal lesions $[4,11]$.

The recently discovered urinary proteins which are markers for AKI are mainly used in experimental studies. Determination of these markers in the medical laboratory requires sensitive, specific and relatively costly immunological methods. Before they are used in practice, the parameters will be subject to numerous validation processes. Guidelines must be developed for standard collection and storage of urine samples. The importance of quick centrifugation of urine after collection is stressed, along with addition of commercially available inhibitors of serine proteases to the supernatant as well as freezing samples and storing them at $-80^{\circ} \mathrm{C}$ until determinations are made [6]. 


\section{Combination of Serum and Urinary Biomarkers for AKI}

It is now a common opinion that there is no single marker to identify damage to different sites within the kidney, assess its severity and predict the clinical course. A more popular approach is to propose instead of a single biomarker a panel of marker proteins to assess renal tubular (dys)function and identify affected segments of the nephron. These proteins differ in their source of origin, expression in the kidney and concentration in urine. The investigations also differ in sensitivity and specificity, technique and cost.

The established panels may find application in several areas $[4,11,13,15,27,28]$ :

(1) distinguishing the types and etiology of AKI;

(2) differentiating between benign, mild, moderate or severe forms of acute renal insufficiency, and

(3) defining the time of onset of kidney injury, duration of AKI and prognosis of renal injury regression.

The most promising panels of markers determined in serum and in urine seem to be the following $[6,17,40,41]$.

- For the differentiation and early diagnosis of AKI:

- increased concentrations of cystatin C in serum, and of IL-18, cystatin C, and KIM-1 in urine,

- increased concentrations of cystatin C in serum, and of IL-18, NGAL, GST- $\pi$ in urine.

- For predicting progress of AKI:

- increased concentrations of actin, IL-6, and IL-8 in urine,
- increased concentrations of actin, IL-6, IL-8, and $\gamma$-glutamyl transpeptidase levels in urine.

- For assessment of severity of AKI:

- increased NAG levels and KIM-1 concentrations in urine.

- For predicting mortality in AKI:

- increased concentrations of KIM-1 and IL-18, and increased NAG levels in urine.

In conclusion, it should be stated that AKI is a continuing problem in clinical medicine, associated with high incidence and mortality. Despite intense search, no single ideal biomarker for AKI has yet been found. The standard laboratory diagnosis of AKI is so far based upon the determination of serum creatinine concentrations but it has proved to be imperfect and insufficient. The proteins determined in serum and urine described above are a clear step forward in the development of science and practice of medicine with potential impact on treatment outcomes on nephrology wards and intensive care units. They are eminent candidates for markers useful in diagnosing AKI, predicting its progress and choosing the best management. At the present stage, however, they require validation and trials in large patient populations.

\section{Acknowledgement}

This research paper was financed from funds for science in the years 2007-2008 as research project N N405 251933.

\section{References}

1 Schrier RW, Wang W, Poole B, Mitra A: Acute renal failure: definitions, diagnosis, pathogenesis, and therapy. J Clin Invest 2004;114:5-14.

2 Venkataraman R, Kellum JA: Defining acute renal failure: the RIFLE criteria. J Intensive Care Med 2007;22:187-193.

-3 Izzedine H, Baumelou A, Deray G: Acute renal failure in HIV patients. Nephrol Dial Transplant 2007;22:2757-2762.

-4 Trof RJ, Di Maggio F, Leemreis J, Groeneveld ABJ: Biomarkers of acute renal injury and renal failure. Shock 2006;26:245-253.

$\checkmark 5$ Westhuyzen J, Endre ZH, Reece G, Reith DM, Saltissi D, Morgan TJ: Measurement of tubular enzymuria facilitates early detection of acute renal impairment in the intensive care unit. Nephrol Dial Transplant 2003;18: 543-551.
-6 Liangos O, Perianayagam MC, Vaidya VS, Han WK, Wald R, Tighiouart H, MacKinnon RW, Li L, Balakrishnan VS, Pereira BJG, Bonventre JV, Jaber BL: Urinary N-acetyl- $\beta$ (D)-glucosaminidase activity and kidney injury molecule-1 level are associated with adverse outcomes in acute renal failure. J Am Soc Nephrol 2007;18:904-912.

-7 Nguyen MT, Devarajan P: Biomarkers for the early detection of acute kidney injury. Pediatr Nephrol 2008;23:2151-2157.

-8 Akcan-Arikan A, Zappitelli M, Loftis LL, Washburn KK, Jefferson LS, Goldstein SL: Modified RIFLE criteria in critically ill children with acute kidney injury. Kidney Int 2007;71:1028-1035.

9 Soni SS, Ronco C, Katz N, Cruz DN: Early diagnosis of acute kidney injury: the promise of novel biomarkers. Blood Purif 2009;28: $165-174$.
10 Bagshaw SM, George C, Dinu I, Bellomo R: A multi-centre evaluation of the Rifle criteria for early acute kidney injury in critically ill patients. Nephrol Dial Transplant 2008; 23:1203-1210.

11 Rabb H: Novel urinary markers for early diagnosis of ARF. Am J Kidney Dis 2003;42: 599-600.

12 Mishra J, Mori K, Ma Q, Kelly C, Yang J, Mitsnefes M, Barasch J, Devarajan P: Amelioration of ischemic acute renal injury by neutrophil gelatinase-associated lipocalin. J Am Soc Nephrol 2004;15:3073-3082.

13 Herget-Rosenthal S, Poppen D, Hüsing J, Marggraf G, Pietruck F, Jakob HG, Philipp T, Kribben A: Prognostic value of tubular proteinuria and enzymuria in nonoliguric acute tubular necrosis. Clin Chem 2004;50:552558 . 
- 14 Becherucci F, Mazzinghi B, Ronconi E, Peired A, Lazzeri E, Sagrinati C, Romagnani P, Lasagni L: The role of endothelial progenitor cells in acute kidney injury. Blood Purif 2009;27:261-270.

-15 Vaidya VS, Ramirez V, Ichimura T, Bobadilla NA, Bonventre JV: Urinary kidney injury molecule-1: a sensitive quantitative biomarker for early detection of kidney tubular injury. Am J Physiol Renal Physiol 2006; 290:F517-F529.

-16 Molls RR, Savransky V, Liu M, Bevans S, Mehta T, Tuder RM, King LS, Rabb H: Keratinocyte-derived chemokine is an early biomarker of ischemic acute kidney injury. Am J Physiol Renal Physiol 2006;290:F1187F1193.

- 17 Dent CL, Ma Q, Dastrala S, Bennett M, Mitsnefes MM, Barasch J, Devarajan P: Plasma neutrophil gelatinase-associated lipocalin predicts acute kidney injury, morbidity and mortality after pediatric cardiac surgery: a prospective uncontrolled cohort study. Crit Care 2007;11:R127.

$\checkmark 18$ Coca SG, Yalavarthy R, Concato J, Parikh CR: Biomarkers for the diagnosis and risk stratification of acute kidney injury: systematic review. Kidney Int 2008;73:1008-1016.

19 Bonventre JV: Diagnosis of acute kidney injury: from classic parameters to new biomarkers. Contrib Nephrol 2007;156:213219.

20 Ricci Z, Ronco C: Today's approach to the critically ill patient with acute kidney injury. Blood Purif 2009;27:127-134.

-21 Wheeler DS, Devarajan P, Ma Q, Harmon K, Monaco M, Cvijanovich N, Wong HR: Serum neutrophil gelatinase-associated lipocalin (NGAL) as a marker of acute kidney injury in critically ill children with septic shock. Crit Care Med 2008;36:1297-1303.

-22 Royakkers AA, van Suijlen JD, Hofstra LS, Kuiper MA, Bouman CS, Spronk PE, Schultz MJ: Serum cystatin C - A useful endogenous marker of renal function in intensive care unit patients at risk for or with acute renal failure? Curr Med Chem 2007;14:2314-2317.

-23 Ejaz AA, Mu W, Kang DH, Roncal C, Sautin YY, Henderson G, Tabah-Fisch I, Keller B, Beaver TM, Nakagawa T, Johnson RJ: Could uric acid have a role in acute renal failure? Clin J Am Soc Nephrol 2007;2:16-21.
24 Nakagawa T, Mazzali M, Kang DH, SánchezLozada LG, Acosta JH, Johnson RJ: Uric acid - A uremic toxin? Blood Purif 2006;24: 67-70.

-25 Branten AJW, Mulder TPJ, Peters WHM, Assmann KJM, Wetzels JFM: Urinary excretion of glutathione $\mathrm{S}$ transferases alpha and pi in patients with proteinuria: reflection of the site of tubular injury. Nephron 2000;85: 120-126.

26 Uchida K, Gotoh A: Measurement of cystatin- $\mathrm{C}$ and creatinine in urine. Clin Chim Acta 2002;323:121-128.

27 Mishra J, Ma Q, Prada A, Mitsnefes M, Zahedi K, Yang J, Barasch J, Devarajan P: Identification of neutrophil gelatinase-associated lipocalin as a novel early urinary biomarker for ischemic renal injury. J Am Soc Nephrol 2003;14:2534-2543.

28 Muramatsu Y, Tsujie M, Kohda Y, Pham B, Perantoni AO, Zhao H, Jo SK, Yuen PST, Craig L, Hu X, Star RA: Early detection of cysteine rich protein 61 (CYR61, CCN1) in urine following renal ischemic reperfusion injury. Kidney Int 2002;62:1601-1610.

29 Han WK, Bailly V, Abichandani R, Thadhani R, Bonventre JV: Kidney injury molecule-1 (KIM-1): a novel biomarker for human renal proximal tubule injury. Kidney Int 2002;62:237-244.

30 Ferguson SM: CYR61 as a marker for acute renal failure. Fed Regist 2003;68:18660.

31 Mishra J, Dent C, Tarabishi R, Mitsnefes MM, Ma Q, Kelly C, Ruff SM, Zahedi K, Shao M, Bean J, Mori K, Barasch J, Devarajan P: Neutrophil gelatinase-associated lipocalin (NGAL) as a biomarker for acute renal injury after cardiac surgery. Lancet 2005;365:12311238.

32 Bolignano D, Coppolino G, Campo S, Aloisi C, Nicocia G, Frisina N, Buemi M: Urinary neutrophil gelatinase-associated lipocalin (NGAL) is associated with severity of renal disease in proteinuric patients. Nephrol Dial Transplant 2008;23:414-416.
33 Timmeren MM, Bakker SJL, Vaidya VS, Bailly V, Schuurs TA, Damman J, Stegeman CA, Bonventre JV, Goor H: Tubular kidney injury molecule-1 in protein-overload nephropathy. Am J Physiol Renal Physiol 2006; 291:F456-F464.

34 Zhang Z, Humphreys BD, Bonventre JV: Shedding of the urinary biomarker kidney injury molecule-1 (KIM-1) is regulated by MAP kinases and juxtamembrane region. J Am Soc Nephrol 2007;18:2704-2714.

-35 Edelstein CL, Hoke TS, Somerset H, Fang W, Klein CL, Dinarello CA, Faubel S: Proximal tubules from caspase-1-deficient mice are protected against hypoxia-induced membrane injury. Nephrol Dial Transplant 2007; 22:1052-1061.

-36 Melnikov VY, Ecder T, Fantuzzi G, Siegmund B, Lucia MS, Dinarello CA, Schrier RW, Edelstein CL: Impaired IL-18 processing protects caspase-1-deficient mice from ischemic renal failure. J Clin Invest 2001;107: 1145-1152.

37 Parikh CR, Abraham E, Ancukiewicz M, Edelstein CL: Urine IL-18 is an early diagnostic marker for acute kidney injury and predicts mortality in the intensive care unit. J Am Soc Nephrol 2005;16:3046-3052.

>38 Washburn KK, Zappitelli M, Arikan AA, Loftis L, Yalavarthy R, Parikh CR, Edelstein CL, Goldstein SL: Urinary interleukin-18 is an acute kidney injury biomarker in critically ill children. Nephrol Dial Transplant 2008; 23:566-572.

39 Schwartz N, Hosford M, Sandoval RM, Wagner MC, Atkinson SJ, Bamburg J, Molitoris BA: Ischemia activates actin depolymerizing factor: role in proximal tubule microvillar actin alterations. Am J Physiol Renal Physiol 1999;276:F544-F551.

40 Kwon O, Molitoris BA, Pescovitz M, Kelly KJ: Urinary actin, interleukin-6, and interleukin-8 may predict sustained ARF after ischemic injury in renal allografts. Am J Kidney Dis 2003;41:1074-1087.

-41 Devarajan P: Emerging biomarkers of acute kidney injury; in Ronco C, Bellomo R, Kellum JA (eds): Acute Kidney Injury. Contrib Nephrol. Basel, Karger, 2007, vol 156, pp 203-212. 